\title{
Pematematikaan Horizontal Siswa SMP pada Masalah Perbandingan
}

\author{
Herna $^{* 1}$, Ana Muliana ${ }^{2}$ \\ ${ }^{1,2}$ Universitas Sulawesi Barat \\ e-mail: ${ }^{* 1}$ hernausb@rocketmail.com, ${ }^{2}$ anamuliana@yahoo.com
}

\begin{abstract}
Abstrak
Penelitian kualitatif ini dilakukan pada siswa kelas VII di SMPN 4 Tinambung, Sulawesi Barat. Tujuannya adalah mengkaji proses proses berpikir siswa dalam pematematikaan horizontal. Penelitian ini menemukan bahwa karateristik berpikir siswa dalam pematematikaan horizontal pada masalah perbandingan meliputi aktivitas modeling dan intertwining. Aktivitas modeling dilakukan dengan menggunakan kata-kata yakni, menyederhanakan soal dengan memperhatikan gambar, kemudian mengaitkan gambar dan keterangan gambar pada soal sehingga diperoleh model soal realistik. Aktivitas intertwining dilakukan dengan mengaitkan soal realistik dengan model yang diperoleh dari soal untuk mengetahui strategi yang akan digunakan dalam menyelesaikan soal. Selanjutnya, siswa mengaitkan situasi dunia nyata dengan konsep matematika, mengaitkan situasi dunia nyata yang satu dengan situasi dunia nyata yang lain, dan mengaitkan konsep matematika yang satu dengan konsep matematika yang lain dalam menjalankan strategi penyelesaian soal.
\end{abstract}

Kata kunci: pematematikaan horizontal, modeling, intertwining, scaffolding

\section{PENDAHULUAN}

Salah satu masalah mendasar dalam pendidikan di indonesia adalah masih rendahnya prestasi siswa dalam belajar matematika. Beberapa laporan menyebutkan faktor penyebabnya, antara lain kurangnya kualitas materi pembelajaran, metode pengajaran yang mekanistik serta buruknya sistem penilaian. Salah satu pendekatan yang menjanjikan dapat mengurangi masalah tersebut adalah realistic mathematics education (RME). Di indonesia dikenal dengan istilah Pendidikan Matematika Realistik Indonesia (PMRI) dalam Lambas, dkk (2004).

Lebih lanjut dalam Lambas, dkk. (2004) menyatakan bahwa RME dikembangkan oleh Freudenthal Institute, Belanda dan koleganya IOWA oleh Freudenthal pada tahun 1977. Menurutnya, matematika harus dihubungkan dengan kenyataan, berada dekat dengan peserta didik, dan relevan dengan kehidupan masyarakat agar memiliki nilai manusiawi. Pandangannya menekankan bahwa materi-materi matematika harus dapat ditransmisikan sebagai aktifitas manusia (human activity). Pendidikan seharusnya memberikan kesempatan peserta didik untuk "re-invent" (menemukan/menciptakan kembali) matematika melalui praktek (doing it). Terkait dengan itu, menurut Gravemeijer (1994) pendekatan 98ealistic penekanannya adalah pada pematematikaan.

Treffers (1991) mengklasifikasikan pematematikaan ke dalam dua tipe yaitu, pematematikaan horizontal dan pematematikaan vertikal. Berdasarkan beberapa pendapat dari De Lange (1987), Treffers (1991), Gravemeijer (1994), dan Yuwono (2001) disimpulkan bahwa pematematikaan horizontal adalah proses membangun konsep matematika informal dari masalah 98ealistic. Aktivitas pematematikaan horizontal meliputi pendeskripsian masalah 98ealistic dalam cara-cara yang berbeda untuk memudahkan menemukan solusi masalah sehingga prosedur penyelesaian masalah atau 
solusi tersebut dapat digunakan kembali untuk menyelesaikan masalah yang sejenis. Singkatnya, menurut Freudenthal dalam Gravemeijer (1994) bahwa pematematikaan horizontal berkaitan dengan perubahan dunia nyata menjadi 99ealis-simbol dalam matematika. Aktivitas pematematikaan horizontal ini dapat berupa modeling (gambar, skema, tabel, kata-kata, self-invented symbols), dan menemukan hubungan-hubungan (intertwining). Sedangkan pematematikaan vertikal berkaitan dengan proses organisasi kembali pengetahuan yang telah diperoleh dalam 99ealis-simbol matematika yang lebih abstrak. Singkatnya, menurut Freudenthal dalam Gravemeijer (1994) pematematikaan vertikal adalah pengubahan dari 99ealis-simbol ke 99ealis matematika lainnya (moving within the world of symbols). Contoh pematematikaan vertikal adalah memperbaiki model, menggunakan model yang berbeda, memadukan dan mengkombinasikan beberapa model, merumuskan konsep matematika yang baru dan penggeneralisasian.

Peneliti bermaksud melakukan penelitian pada kelas VII. Peneliti menfokuskan penelitiannya pada pematematikaan horizontal. Hal ini disebabkan siswa pada kelas tersebut pada umumnya berumur 11-12 tahun, dimana menurut Piaget dalam Budiningsih (2005) usia seseorang 7-12 tahun berada pada tahap operasi konkret sehingga dalam belajar siswa tersebut masih membutuhkan pengaitan antara pengetahuan yang dipelajari dengan kehidupan nyata agar siswa dapat memahami pengetahuan tersebut dengan baik. Selain itu, pematematikaan horizontal merupakan langkah awal dari proses re-invent (menemukan/menciptakan kembali) sebuah konsep matematika sehingga siswa diharuskan dapat melakukan pematematikaan horizontal dengan baik agar proses reinventnya berjalan dengan 99ealis.

Dalam penelitian ini, pematematikaan horizontal dimaksudkan sebagai alur membangun konsep matematika informal. Konsep matematika yang akan dikonstruksi dan ditemukan kembali dalam penelitian ini adalah konsep perbandingan informal. Alasan dipilihnya konsep tersebut karena masalah perbandingan banyak ditemui dalam kehidupan sehari-hari sehingga tepat digunakan untuk penerapan pematematikaan horizontal.

Pematematikaan horizontal dalam penelitian ini ditunjukkan oleh jawaban siswa dalam menyelesaikan masalah kontekstual sehingga pematematikaan horizontal mempunyai kemungkinan salah atau benar. Terkait dengan itu, pematematikaan horizontal yang benar yang dilakukan oleh siswa perlu dicari tahu karena dapat memperkuat agar pematematikaan horizontal selanjutnya senantiasa benar. Sedangkan, pematematikaan horizontal yang salah yang dilakukan oleh siswa perlu juga dicari tahu untuk mencari letak kesahalannya agar dapat dibenahi.

Dalam melakukan pematematikaan horizontal, ada beberapa kemungkinan jawaban dari siswa yaitu, ada siswa yang dapat melakukan aktivitas pematematikaan horizontal dengan benar tanpa bantuan dari peneliti, ada siswa yang dapat melakukan aktivitas pematematikaan horizontal dengan benar jika diberikan bantuan oleh peneliti, dan ada siswa yang tidak dapat melakukan aktivitas pematematikaan horizontal dengan benar meskipun diberikan bantuan oleh peneliti.

Hudojo (1990) berpendapat bahwa di dalam proses belajar matematika terjadi juga proses berpikir, sebab seseorang dikatakan berpikir bila orang itu melakukan kegiatan mental dan orang yang belajar matematika mesti melakukan kegiatan mental. Terkait dengan pernyataan itu maka dalam mengonstruksi sebuah pengetahuan siswa mesti melakukan kegiatan mental 99ealistic99 mengkonstruksi sebuah pengetahuan merupakan hal yang penting dalam pembelajaran maka penting untuk mengetahui proses berpikir siswa dalam mengkonstruksi pengetahuan tersebut.

Karakteristik berpikir siswa dalam melakukan aktivitas pematematikaan horizontal perlu diketahui agar dapat mengkonstruksi lembar aktivitas yang sesuai dengan 
cara berpikir siswa sehingga memudahkan proses konstruksi konsep matematika. Selain itu, karakteristik berpikir siswa ketika diberikan bantuan juga perlu diketahui sebagai bahan pertimbangan untuk alternatif bantuan yang akan diberikan ketika siswa mengalami kesulitan dalam mengkonstruksi konsep matematika sehingga proses konstruksinya berjalan dengan baik.

Vincent Ruggiero dalam Subanji (2007) mengartikan berpikir sebagai aktivitas mental yang membantu merumuskan atau memecahkan masalah, membuat keputusan, atau memenuhi keinginan untuk memahami. Berpikir dalam penelitian ini di maksudkan sebagai aktivitas mental dalam membangun konsep perbandingan informal dari masalah 100ealistic.

Berdasarkan kegiatan prasurvey yang dilakukan peneliti pada tanggal 20 Januari 2010, peneliti menemukan bahwa karakteristik berpikir siswa dalam melakukan pematematikaan horizontal terkait konsep perbandingan informal meliputi modeling, dan intertwining. Hal tersebut diketahui setelah siswa mendapatkan scaffolding dari peneliti, karena siswa mengalami kesulitan dalam melakukan aktivitas tersebut secara individu.

Terkait dengan pernyataan di atas maka karakteristik berpikir siswa yang akan diamati dalam penelitian ini adalah karakteristik berpikir siswa ketika melakukan aktivitas pematematikaan horizontal yaitu, modeling dan intertwining. Pendeskripsian karakteristik berpikir siswa pada pematematikaan horizontal dimaksudkan dengan mendeskripsikan hasil eksplorasi berpikir siswa dalam melakukan aktivitas pematematikaan horizontal untuk mengetahui karakteristik berpikir dari masing-masing subjek penelitian, demi tujuan lebih jauh yaitu, menemukan karakteristik berpikir siswa dalam melakukan aktivitas modeling dan intertwining untuk masing-masing kategori (kelompok tinggi, kelompok sedang, dan kelompok rendah).

Dalam penelitian ini, peneliti akan mengkaji proses berpikir siswa dalam pematematikaan horizontal melalui scaffolding, dan kemudian mengidentifikasi karakteristik berpikir siswa ketika melakukan aktivitas pematematikaan tersebut. Hal ini dilandasi oleh pemikiran bahwa dalam melakukan aktivitas pematematikaan horizontal siswa mengalami kesulitan seperti yang ditemukan peneliti ketika melakukan kegiatan prasurvey.

Menurut Lambas, dkk. (2004) bantuan dari seseorang yang lebih dewasa atau lebih kompeten dengan maksud agar si anak mampu untuk megerjakan tugas-tugas atau soal-soal yang lebih tinggi tingkat kerumitannya daripada tingkat perkembangan kognitif yang aktual dari anak yang bersangkutan disebut dukungan dinamis atau scaffoding. Scaffolding berarti memberikan sejumlah besar bantuan kepada siswa selama tahap-tahap awal pembelajaran dan kemudian mengurangi bantuan tersebut dan memberikan kesempatan kepada siswa untuk mengambil alih tanggung jawab yang semakin besar segera setelah ia dapat melakukannya. Bentuk dari bantuan itu berupa petunjuk, peringatan, dorongan, penguraian langkah-langkah pemecahan, pemberian contoh, atau segala sesuatu yang dapat mengakibatkan siswa mandiri. Pernyataan tersebut sejalan dengan pendapat Wood, Bruner \& Ross dalam Julia Anghileri (2006) yang menyatakan bahwa: "The notion of "scaffolding" has been used to reflect the way adult support is adjusted as the child learns and is ultimately removed when the learner can "stand alone",". Dalam penelitian ini, scaffolding diberikan oleh peneliti.

Terkait dengan pernyataan sebelumnya bahwa dalam melakukan kegiatan prasurvey peneliti menemukan bahwa aktivitas pematematikaan horizontal yang dilakukan oleh siswa dalam membangun konsep perbandingan informal adalah modeling, dan intertwining maka untuk mengetahui bagaimana karakteristik berpikir siswa dalam melakukan masing-masing aktivitas tersebut, peneliti bermaksud melakukan penelitian 
lebih lanjut tentang "Proses Berpikir Siswa dalam Pematematikaan Horizontal melalui Scaffolding".

\section{METODE PENELITIAN}

Penelitian ini menggunakan pendekatan kualitatif dan tergolong penelitian deskriptif eksploratif. Hal tersebut disebabkan penelitian ini mendeskripsikan hasil eksplorasi proses atau tingkah laku siswa dalam menyelesaikan masalah matematika. Penelitian ini dilakukan di SMP Negeri 4 Tinambung, kabupaten POLMAN provinsi SULBAR. Peneliti melakukan kegiatan prasurvey dengan tujuan untuk mengetahui nilai matematika semester gasal siswa kelas VIIB dan untuk memperkenalkan diri pada calon siswa yang akan menjadi subjek penelitian. Kemudian dengan bantuan guru dan berdasar pada nilai raport serta pertimbangan sifat komunikatif dari siswa, peneliti kemudian menentukan subjek penelitian yang terdiri atas: 2 siswa dari kelompok tinggi, 2 siswa dari kelompok sedang, dan 2 siswa dari kelompok rendah. Selain itu, pada tahap ini juga dilakukan uji pendahuluan pada kelas VII C dengan tujuan untuk memastikan bahwa terjadi aktivitas mental ketika siswa melakukan pematematikaan horizontal masalah perbandingan. Selain itu, uji pendahuluan ini juga bertujuan untuk melihat apakah masalah yang tercantum dalam instrumen lembar tugas dapat dipahami oleh siswa untuk keperluan penyempurnaan instrumen lembar tugas.

Pada tahap pengambilan data, peneliti bekerjasama dengan guru bidang studi matematika kelas VIIB untuk melakukan pengambilan data. Pada saat pengambilan data, peneliti menggunakan dua alat perekam yaitu, falsh disk dan kamera digital. Flash disk digunakan untuk merekam suara dan kamera digital digunakan untuk melihat perilaku siswa. Selain itu, peneliti juga membuat catatan kejadian unik, misalnya ketika siswa berpikir keras sambil memegang kepala, siswa merenungkan masalah dengan diam, dan sebagainya. Pada saat pengambilan data, apabila peneliti merasa perlu untuk mendalami berpikir siswa maka dilakukan dengan mewawancarainya pada saat itu. Dari hasil rekaman di flash disk ditransfer ke komputer dan kemudian ditranskrip.

Setelah diperoleh data (hasil TOL, dan hasil wawancara), maka peneliti menganalisis data dengan mereduksi data, pengkodean, dan menggambarkan diagram struktur berpikir siswa. Setelah itu, peneliti mencari tahu karakteristik berpikir masingmasing siswa yang menjadi subjek penelitian dalam melakukan pematematikaan horizontal dan menggunakan metode perbandingan tetap untuk menemukan karakteristik berpikir siswa dalam pematematikaan horizontal pada setiap kelompok subjek (kelompok tinggi, sedang, dan rendah).

\section{HASIL PENELITIAN DAN PEMBAHASAN}

Dari hasil kajian berpikir siswa dalam melakukan pematematikaan horizontal masalah perbandingan dapat disimpulkan bahwa karateristik berpikir siswa dalam pematematikaan horizontal meliputi aktivitas modeling dan intertwining.

Aktivitas modeling dilakukan dengan menggunakan kata-kata yakni, menyederhanakan soal dengan memperhatikan gambar, kemudian mengaitkan gambar dan keterangan gambar pada soal sehingga diperoleh model soal realistik yakni berat 2 buah nanas sama dengan berat 10 buah pisang, berat 1 buah nanas sama dengan berat 2 buah pisang dan 1 buah apel, dan berat semua ayam betina yang akan dinaikkan ke sisi kiri timbangan agar timbangan dalam kondisi seimbang adalah 1600 gram. Aktivitas intertwining dilakukan dengan mengaitkan soal realistik dengan model yang diperoleh dari soal untuk mengetahui strategi yang akan digunakan dalam menyelesaikan soal. 
Selanjutnya, siswa mengaitkan situasi dunia nyata dengan konsep matematika, mengaitkan situasi dunia nyata yang satu dengan situasi dunia nyata yang lain, dan mengaitkan konsep matematika yang satu dengan konsep matematika yang lain dalam menjalankan strategi penyelesaian soal.

Karakteristik berpikir siswa dalam mengaitkan situasi dunia nyata dengan konsep matematika berupa, menemukan hubungan antara situasi dunia nyata (berat 1 buah apel, gram lebihnya atau kurangnya berat buah) dan konsep pengurangan, menemukan hubungan antara situasi dunia nyata (berat 1 buah nanas, berat buah yang satu berapa kali berat buah yang lain) dan konsep pembagian, menemukan hubungan antara buah yang lebih berat atau lebih ringan dan konsep urutan bilangan riil, dan menemukan hubungan antara berat ayam dan konsep penjumlahan. Semua pengaitan yang telah disebutkan adalah tepat, dan dapat dilakukan siswa dengan baik. Selain pengaitan yang telah disebutkan di atas, siswa juga menemukan hubungan antara berat buah yang satu berapa kali berat buah yang lain dan konsep pembagian. Pengaitan ini pun tepat digunakan untuk menyelesaikan soal, namun siswa tidak dapat melakukan aktivitas tersebut dengan baik. Hal tersebut disebabkan oleh urutan bilangan ketika melakukan operasi pembagian terbalik, dan itu menunjukkan bahwa siswa tidak memahami pernyataan tentang "berat buah yang satu sekian kali berat buah yang lain" dengan baik.

Karakteristik berpikir siswa dalam mengaitkan situasi dunia nyata yang satu dengan situasi dunia nyata yang lain berupa, menemukan hubungan antara cara membandingkan berat buah pada soal yang satu dan soal lainnya yang sejenis. Pengaitan tersebut tepat digunakan untuk menyelesaikan soal, dan siswa dapat melakukannya dengan baik.

Karakteristik berpikir siswa dalam mengaitkan konsep matematika yang satu dan konsep matematika yang lain berupa, menemukan hubungan konsep pecahan sederhana dan konsep pembagian dalam menyederhanakan pecahan, dan menemukan hubungan antara konsep penjumlahan dan konsep satuan sejenis dalam menghitung berat ayam yang satuannya berbeda. Pengaitan tersebut tepat digunakan untuk menyelesaikan soal, dan siswa dapat melakukannya dengan baik.

Berikut salah satu contoh kajian proses berpikir siswa dalam melakukan aktivitas modeling dan intertwining dalam menyelesaian masalah pada instrumen penelitian.

Dalam menyelesaikan soal nomor 1(a) secara individu, siswa hanya melakukan aktivitas intertwining. Aktivitas intertwining tersebut adalah intertwining antara situasi dunia nyata dan konsep urutan bilangan riil. Dalam situasi dunia nyata, siswa $R_{2}$ menentukan buah apa yang lebih berat antara buah nanas dengan buah pisang yang ada pada diagram (1) jika banyaknya buah pisang 10 buah dan banyaknya buah nanas 2 buah, sehingga ditemukan bahwa buah yang lebih berat adalah buah pisang karena buah nanas lebih banyak dari buah pisang. Jawaban yang diperoleh dari aktivitas tersebut adalah salah karena siswa membandingkan berat 2 buah nanas dengan 10 buah pisang, sedangkan yang diminta dalam soal adalah membandingkan berat 1 buah pisang dengan berat 1 buah nanas. Berikut adalah jawaban siswa yang mendukung pernyataan tersebut.


berikut ini.

Pernyataan tersebut juga didukung oleh hasil transkrip ungkapan verbal siswa

S: $\quad$ Buah pisang karena buah nanas lebih sedikit 50 gram

P: $\quad$ Apa maksudnya buah nanas lebih sedikit 50 gram?

S: $\quad$ Karena buah pisang 10, dan buah nanas 2, jadi buah pisang lebih berat karena lebih banyak 
Untuk menjawab pertanyaan selanjutnya, siswa melakukan intertwining antara kata gram yang ada dalam kalimat pertanyaan dan apa yang diketahui dalam soal yakni, berat 1 buah pisang 50 gram, sehingga siswa menjawab bahwa gram lebihnya adalah 50 gram. Jawaban yang diperoleh dari aktivitas tersebut masih salah karena siswa menjawab pertanyaan tersebut dengan mengambil begitu saja nilai yang mengikuti satuan gram hanya karena dalam kalimat pertanyaan ada kata gram, sedangkan yang diminta dalam soal adalah menentukan berat 1 buah nanas terlebih dahulu kemudian menentukan berapa gram lebihnya berat buah yang satu dengan berat buah yang lain jika diketahui dalam soal bahwa berat 1 buah pisang 50 gram. Berikut adalah pernyataan siswa yang mendukung pernyataan tersebut.

$$
\begin{array}{ll}
P: & \text { Kira-kira dari mana kamu dapat } 50 \text { gram? } \\
S: & \text { Saya melihat di soal ada } 50 \text { gram Bu } \\
P: & \text { Jadi kamu langsung mengambilnya begitu saja? } \\
& \text { (Sambil tersenyum siswa menjawab) } \\
S: & \text { iya Bu }
\end{array}
$$

Selain itu, siswa juga melakukan aktivitas intertwining antara kata "lebih" dalam pertanyaan (a), bilangan-bilangan yang ada dalam soal dan konsep penjumlahan untuk menjawab pertanyaan "bagaimana cara menghitungnya?". Jawaban yang diperoleh dari aktivitas tersebut masih salah karena siswa menjawab pertanyaan tersebut dengan menjumlahkan setiap bilangan yang ada dalam soal hanya karena dalam kalimat pertanyaan tersebut terdapat kata "lebih", sedangkan yang diminta oleh soal adalah menjelaskan cara menghitung berapa gram lebihnya berat buah yang satu dengan buah yang lain jika berat dari masing-masing buah telah diketahui. Berikut adalah jawaban siswa yang mendukung pernyataan tersebut.

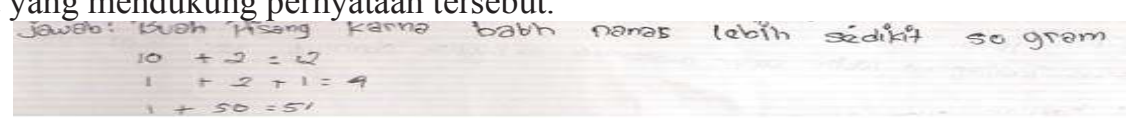
berikut ini.

Pernyataan tersebut juga didukung oleh hasil transkrip ungkapan verbal siswa

$$
\begin{array}{ll}
P: & \text { Apa maksud dari } 10+2=12,1+2+1=4,1+50=51 ? \\
\text { (sambil tersenyum lagi siswa menjawab) } & \text { Karena pertanyaannya adalah berapa gram lebihnya, maka saya } \\
\text { menjumlahkan setiap bilangan dalam soal, } 10 \text { buah pisang }+2 \text { buah } \\
\text { nanas, } 1 \text { buah nanas ditambah } 2 \text { buah pisang tambah } 1 \text { buah apel, } 1 \\
\text { buah pisang tambah } 50 \text { gram }
\end{array}
$$

Berdasarkan jawaban siswa di atas, peneliti menemukan bahwa siswa tidak memahami soal dengan baik, dan semua intertwining yang dilakukan belum tepat dan tidak bermakna.

Berdasarkan pemaparan di atas, dapat disajikan struktur berpikir siswa dalam menyelesaikan soal nomor 1 bagian (a) dalam diagram berikut ini. Selain itu, struktur berpikir siswa juga dibandingkan dengan struktur masalah agar dapat diketahui apakah siswa membutuhkan scaffolding dari peneliti atau tidak. 




Diagram 1 Struktur Berpikir Siswa $\mathrm{R}_{2}$ dalam Menyelesaikan Soal Nomor 1(a) Secara Individu

Keterangan:

\begin{tabular}{|l|c|}
\hline \multicolumn{1}{|c|}{ Istilah } & Kode \\
\hline Banyaknya buah pisang yang dibandingkan adalah 10 buah & $\mathbf{P i}_{\mathbf{1 0}}$ \\
\hline Banyaknya buah nanas yang dibandingkan adalah 2 buah & $\mathbf{N}_{\mathbf{2}}$ \\
\hline Banyaknya buah pisang =10 buah $>$ 2 buah = banyaknya buah nanas & $\mathbf{O U}_{\mathbf{1}}$ \\
\hline Buah yang lebih berat adalah buah pisang & $\mathbf{J U}_{\mathbf{1}}$ \\
\hline $\begin{array}{l}\text { Penjumlahan setiap bilangan yang ada dalam soal yakni, 10+2, 1+2+1, } \\
1+50\end{array}$ & $\mathbf{O L}$ \\
\hline Gram lebihnya adalah 50 gram & $\mathbf{J L}$ \\
\hline $\begin{array}{l}\text { Aktivitas intertwining antara situasi dunia nyata dan konsep urutan } \\
\text { bilangan riil. Dalam situasi dunia nyata, siswa menentukan buah apa yang } \\
\text { lebih berat antara buah pisang dengan buah nanas yang ada pada gambar } \\
\text { (1) jika banyaknya buah pisang 10 buah, dan banyaknya buah nanas } 2 \\
\text { buah }\end{array}$ & $\mathbf{I n t}_{\mathbf{P}}$ \\
\hline $\begin{array}{l}\text { Aktivitas intertwining antara kata gram yang ada dalam kalimat pertanyaan } \\
\text { dan apa yang diketahui dalam soal yakni, berat 1 buah pisang 50 gram }\end{array}$ & $\mathbf{I n t}_{\mathbf{e} \mathbf{1}}$ \\
\hline $\begin{array}{l}\text { Aktivitas intertwining antara kata "lebih" dalam soal, bilangan-bilangan } \\
\text { yang ada dalam soal dan konsep penjumlahan untuk menjawab pertanyaan } \\
\text { "bagaimana cara menghitungnya?" }\end{array}$ & $\mathbf{I n t}_{\mathbf{e} \mathbf{2}}$ \\
\hline
\end{tabular}

Karena struktur berpikir siswa tidak sesuai dengan struktur masalah seperti yang ditunjukkan oleh tulisan dan bentuk bintang yang diblok pada diagram di atas, maka peneliti perlu memberikan scaffolding.

\section{KESIMPULAN}

Berdasarkan hasil penelitian dan pembahasan sebelumnya, peneliti menyimpulkan bahwa dalam melakukan pematematikaan horizontal masalah perbandingan dapat disimpulkan bahwa karateristik berpikir siswa dalam pematematikaan horizontal meliputi aktivitas modeling dan intertwining.

Aktivitas modeling dilakukan dengan menggunakan kata-kata yakni, menyederhanakan soal dengan memperhatikan gambar, kemudian mengaitkan gambar 
dan keterangan gambar pada soal sehingga diperoleh model soal realistik yakni berat 2 buah nanas sama dengan berat 10 buah pisang, berat 1 buah nanas sama dengan berat 2 buah pisang dan 1 buah apel, dan berat semua ayam betina yang akan dinaikkan ke sisi kiri timbangan agar timbangan dalam kondisi seimbang adalah 1600 gram. Aktivitas intertwining dilakukan dengan mengaitkan soal realistik dengan model yang diperoleh dari soal untuk mengetahui strategi yang akan digunakan dalam menyelesaikan soal. Selanjutnya, siswa mengaitkan situasi dunia nyata dengan konsep matematika, mengaitkan situasi dunia nyata yang satu dengan situasi dunia nyata yang lain, dan mengaitkan konsep matematika yang satu dengan konsep matematika yang lain dalam menjalankan strategi penyelesaian soal.

\section{DAFTAR PUSTAKA}

Budiningsih, C. A. 2005. Belajar dan Pembelajaran. Jakarta: Rineka Cipta.

Creswell, John W. 2012. Research Desain Pendekatan Kualitatif, Kuantitatif, dan Mixed. Yogyakarta: Pustaka Belajar.

De Lange, J. 1987. Mathematics, Insight and Meaning. CW \& OC, Utrecht.

Gravemeijer, K. 1994. Developing Realistic Mathematics Education. Utrecht: Freudental Institute.

Hudojo. 1990. Heboh tentang Pengajaran Matematika di SD. Makalah disajikan pada seminar regional matematika kota Malang, 20 September.

Julia Anghileri, 2006. Scaffolding Practices that Enhance Mathematics Learning.

Lambas, dkk. 2004. Materi Pelatihan Terintegrasi (Matematika). Jakarta: Dirjen Dikdasmen.

Ruggiero, Vincent Ryan. 2012. Beyond feelings: A guide to Critical Thinking $9^{\text {th }}$ Edition. New York: McGraw-Hill Companies,Inc.

Subanji. 2007. Proses Berpikir Penalaran Kovriasional Pseudo dalam Mengkonstruksi Grafik Fungsi Kejadian Dinamika Berkebalikan. Disertasi tidak dipublikasikan, Surabaya: Program Pascasarjana UNESA.

Treffers. A.1991. didactical Background of Mathematical Program for Primary Education. Freudenthal Institute. Utrecht.

Yuwono, I. 2001."RME (Realistics Mathematics Education) dan Hasil Studi awal Implementasinya di SLTP". Makalah Seminar disajikan pada Seminar Nasional Realistics Mathematic Education (RME) di UNESA Surabaya, 24 Pebruari 2001. 